\title{
Multi-epitope TARP-pulsed Autologous Dendritic Cell Vaccine
}

National Cancer Institute

\section{Source}

National Cancer Institute. Multi-epitope TARP-pulsed Autologous Dendritic Cell Vaccine.

NCI Thesaurus. Code C85470.

A cell-based cancer vaccine comprised of autologous dendritic cells pulsed with multiple antigenic peptides derived from $\mathrm{T}$-cell receptor gamma-chain alternate reading frame protein (TARP), with potential immunostimulatory and antineoplastic activities. Upon intradermal administration, multi-epitope (ME) TARP-pulsed autologous dendritic cell vaccine may stimulate anti-tumor cytotoxic T-lymphocyte (CTL) and antibody responses against TARP-expressing cancer cells, resulting in tumor cell lysis. The highly immunogenic nuclear protein TARP is expressed in a variety of cancer cell types. 